\title{
Periderm: Life-cycle and function during orofacial and epidermal development
}

DOI:

10.1016/j.semcdb.2017.08.021

\section{Document Version}

Accepted author manuscript

Link to publication record in Manchester Research Explorer

\section{Citation for published version (APA):}

Hammond, N., Dixon, J., \& Dixon, M. (2017). Periderm: Life-cycle and function during orofacial and epidermal development. Seminars in Cell and Developmental Biology. https://doi.org/10.1016/j.semcdb.2017.08.021

\section{Published in:}

Seminars in Cell and Developmental Biology

\section{Citing this paper}

Please note that where the full-text provided on Manchester Research Explorer is the Author Accepted Manuscript or Proof version this may differ from the final Published version. If citing, it is advised that you check and use the publisher's definitive version.

\section{General rights}

Copyright and moral rights for the publications made accessible in the Research Explorer are retained by the authors and/or other copyright owners and it is a condition of accessing publications that users recognise and abide by the legal requirements associated with these rights.

\section{Takedown policy}

If you believe that this document breaches copyright please refer to the University of Manchester's Takedown Procedures [http://man.ac.uk/04Y6Bo] or contact uml.scholarlycommunications@manchester.ac.uk providing relevant details, so we can investigate your claim.

\section{OPEN ACCESS}




\section{Accepted Manuscript}

Title: Periderm: life-cycle and function during orofacial and epidermal development

Authors: Nigel L. Hammond, Jill Dixon, Michael J. Dixon

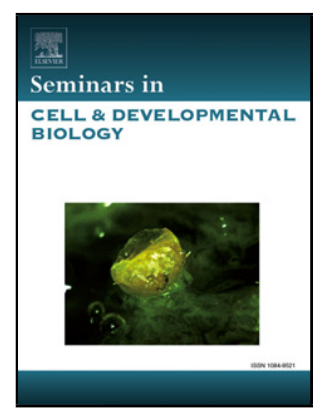

PII:

S1084-9521(17)30377-4

DOI:

http://dx.doi.org/doi:10.1016/j.semcdb.2017.08.021

Reference:

YSCDB 2330

To appear in: $\quad$ Seminars in Cell \& Developmental Biology

Received date: $\quad 26-6-2017$

Revised date: $\quad 1-8-2017$

Accepted date: $\quad$ 6-8-2017

Please cite this article as: Hammond Nigel L, Dixon Jill, Dixon Michael J.Periderm: life-cycle and function during orofacial and epidermal development.Seminars in Cell and Developmental Biology http://dx.doi.org/10.1016/j.semcdb.2017.08.021

This is a PDF file of an unedited manuscript that has been accepted for publication. As a service to our customers we are providing this early version of the manuscript. The manuscript will undergo copyediting, typesetting, and review of the resulting proof before it is published in its final form. Please note that during the production process errors may be discovered which could affect the content, and all legal disclaimers that apply to the journal pertain. 
Periderm: life-cycle and function during orofacial and epidermal development

Nigel L. Hammond, Jill Dixon, Michael J. Dixon*

*To whom correspondence should be addressed: mike.dixon@manchester.ac.uk

Faculty of Biology, Medicine \& Health

Manchester Academic Health Sciences Centre

Michael Smith Building

University of Manchester

Oxford Road

Manchester

M13 9PT

United Kingdom 


\section{Abstract}

Development of the secondary palate involves a complex series of embryonic events which, if disrupted, result in the common congenital anomaly cleft palate. The secondary palate forms from paired palatal shelves which grow initially vertically before elevating to a horizontal position above the tongue and fusing together in the midline via the medial edge epithelia. As the epithelia of the vertical palatal shelves are in contact with the mandibular and lingual epithelia, pathological fusions between the palate and the mandible and/or the tongue must be prevented. This function is mediated by the single cell layered periderm which forms in a distinct and reproducible pattern early in embryogenesis, exhibits highly polarised expression of adhesion complexes, and is shed from the outer surface as the epidermis acquires its barrier function.

Disruption of periderm formation and/or function underlies a series of birth defects that exhibit multiple inter-epithelial adhesions including the autosomal dominant popliteal pterygium syndrome and the autosomal recessive cocoon syndrome and Bartsocas Papas syndrome. Genetic analyses of these conditions have shown that IRFG, IKKA, SFN, RIPK4 and GRHL3, all of which are under the transcriptional control of $p 63$, play a key role in periderm formation.

Despite these observations, the medial edge epithelia must rapidly acquire the capability to fuse if the palatal shelves are not to remain cleft. This process is driven by TGF 33 -mediated, downregulation of $\mathrm{p} 63$ in the medial edge epithelia which allows periderm migration out of the midline epithelial seam and reduces the proliferative potential of the midline epithelial seam thereby preventing cleft palate. Together, these findings indicate that periderm plays a transient but fundamental role during embryogenesis in preventing pathological adhesion between intimately apposed, adhesion-competent epithelia.

Keywords: Periderm; ectoderm; palatal fusion; cleft palate; pterygium syndromes 


\section{Introduction}

Development of the secondary palate, which ultimately divides the oro-nasal space into separate oral and nasal cavities, involves a complex series of integrated events that requires close coordination of developmental programmes for cell migration, growth, adhesion, differentiation and apoptosis. Failure of these processes results in the congenital anomaly cleft palate which has an estimated incidence of 1 in 2500 live births [1,2]. Cleft palate results in considerable morbidity to affected individuals as they may experience problems with feeding, obstructive apnoea, speaking, hearing and social adjustment which can be improved to varying degrees by airway support, surgery, speech therapy, dental treatment, and psychosocial intervention [1,2]. The frequent occurrence and major healthcare burden imposed by cleft palate highlight the need to dissect the fundamental mechanisms that underlie development of the secondary palate.

Cleft palate has a strong genetic component with over $50 \%$ of cases occurring with additional noncleft abnormalities as part of a syndrome [3]. Over 500 syndromic forms of cleft palate have been described, most of which result from single gene mutations or chromosomal abnormalities. Identification of the genetic mutations underlying syndromic forms of cleft palate allied to developmental studies using appropriate animal models is central to our understanding of the gene regulatory networks underlying palatal development and the pathogenesis of cleft palate.

\section{Palatal development}

Development of the secondary palate in mice closely mirrors that occurring in humans; consequently, the mouse is the main model organism used for studying palatogenesis [4-6]. In mice, palatal shelves initiate from the maxillary processes on embryonic day (E) 11 and grow vertically, lateral to the tongue, during E12 and E13 (Fig. 1). At these stages, each palatal shelf consists of a core of neural crest cell-derived mesenchyme surrounded by a simple, undifferentiated epithelium consisting of a basal layer of cuboidal ectodermal cells and a surface layer of flattened periderm cells similar to the remainder of the oral epithelia and the epidermis $[7,8]$. During E14, the palatal shelves rapidly re-orientate to a horizontal position above the dorsum of the tongue and contact via their medial edge epithelia (Fig. 1). The medial edge epithelia of the apposed palatal shelves adhere to form a midline epithelial seam which is subsequently removed to allow mesenchymal continuity across the palate by E15 (Fig. 1).

Although the epithelia of the vertical palatal shelves are in intimate contact with the mandibular and lingual epithelia, pathological fusions between the palate and the mandible and/or the tongue are rare [9-11]; nevertheless, the medial edge epithelia must rapidly acquire the capability to fuse if the palatal shelves are not to remain cleft. Although the mechanisms by which removal of the midline seam is ultimately completed have been controversial, the prevailing evidence now supports a major role for cell death with epithelial-mesenchymal transformation playing only a minor, if any, role [6,12-14] Recent evidence has suggested that removal of the periderm from the midline epithelial seam is a pre-requisite for palatal fusion to be completed successfully; inhibition of periderm elimination resulting in prevention of medial edge epithelial cell death and cleft palate [13]. These observations indicate that competence for oral and palatal shelf adhesion is precisely regulated; however, the mechanisms that control this process are only partially characterised.

\section{Periderm life-cycle}


During embryogenesis, the immature ectoderm progress through a series of defined stratification and differentiation events to produce the mature epidermis, the first of which results in periderm formation (Fig. 2). Unlike later stratification events which result from asymmetric cell division [15], periderm formation commences at multiple sites as a subset of the cuboidal ectodermal cells express keratin 17, extend cellular processes over their neighbouring cells, lose contact with the basement membrane, and migrate over the basal cells to form a surface layer of flattened, endothelial-like cells $[16,17]$ (Fig. 2). Periderm is observed first over the tail and limbs before spreading in a wave over the face and torso such that the embryo is covered by E14 $[16,18]$. Similar to the epidermis, oral periderm forms in a patterned manner, initially over the developing facial complex at E10.5 and later over the palatal shelves [18].

From E16-E17, formation of the metabolically-inactive cornified layer results in acquisition of a highly competent barrier that prevents water loss, entry of toxins, and microbial invasion. At this stage, periderm disaggregates in a patterned manner that recapitulates barrier formation due to loss of contact with the terminally-differentiated keratinocytes [18-22] (Fig. 2).

\section{Periderm function}

Insights into the function of periderm arose from analysis of mice carrying mutations in the gene encoding Interferon Regulatory Factor 6; IRF6. Mice homozygous for either the Arg84Cys mutation, which abrogates DNA binding, or a loss-of-function allele, exhibit a hyper-proliferative epidermis that fails to undergo terminal differentiation resulting in absence of the granular and cornified layers $[23,24]$. Consequently, desmosomes are present in the most superficial layers of the mutant epidermis leading to multiple inter-epithelial adhesions that result in the hind-limbs, tail and body wall adhering to one another, the lumen of the oesophagus being obliterated, and cleft palate resulting from severe intra-oral epithelial adhesions [23,24].

Despite these observations, the phenotype was apparent prior to the onset of terminal differentiation with abnormally shortened, curved limb-buds and oral adhesions observed at E12. Notably, an identical phenotype was observed in mice carrying mutations in the genes encoding IKB kinase- $\alpha$ (IKK $\alpha$ ) and the cell cycle regulator protein stratifin (SFN) [25-29] with periderm shown to be absent in all three strains [18]. By immunostaining with antibodies against a panel of adhesion complex proteins, Richardson and colleagues subsequently demonstrated that prior to periderm formation the apical surfaces of the naïve ectoderm cells were not adhesion-competent in either wild-type or mutant mice [18] (Fig. 3). As development progressed, the presence of tight junctions at the apico-lateral borders of the periderm cells provided a 'fence function' to prevent spread of adhesion complexes onto the apical surface in wild-type embryos (Fig. 3). In contrast, the mutant mice failed to develop periderm resulting in cell adhesion molecules being expressed on the apical membrane of exposed basal cells [18] (Fig. 3).Ultrastructural analysis confirmed the absence of periderm and revealed a statistically-significant increase in apical protrusions from the exposed basal cells in Irf6 ${ }^{\mathrm{R} 4 \mathrm{C} / \mathrm{R84C}}$ embryos. Moreover, in regions where adjacent epithelial surfaces were in close proximity, such as in the oral cavity, the epithelial protrusions established contact and were connected by desmosomes [18]. These observations indicate that periderm cells act as a protective barrier which prevents pathological adhesion between intimately apposed, adhesion-competent epithelia: in essence, periderm acts as a protective 'non-stick' coat. Further support for this function was provided by the observation that mosaic ablation of periderm using a genetic strategy resulted in intra-oral adhesions between the maxillary and mandibular processes. Although these adhesions 
were generally limited to the lateral regions of the oral cavity, in severe cases they prevented normal development of the palatal shelves resulting in cleft palate [18].

\section{Peridermopathies}

Further support for the periderm acting as a protective barrier during embryogenesis was provided by the observation that failure of periderm formation underlies the popliteal pterygia syndromes; a series of devastating human congenital disorders characterised by cutaneous webbing across one or more major joints, cleft lip and/or palate, syndactyly, and genital malformations. These conditions include Van der Woude syndrome, popliteal pterygium syndrome, Bartsocas Papas syndrome, and cocoon syndrome which result from mutations in IRF6, IKKA and RIPK4 [30-34].

Van der Woude syndrome, an autosomal dominant disorder characterised by cleft lip and palate with lip pits, is the most common syndromic form of cleft lip and/or palate accounting for approximately $2 \%$ of all cases [2]. Popliteal pterygium syndrome is a more severe allelic disorder that presents with a similar orofacial phenotype and additional features including bilateral popliteal webs, syndactyly, genital anomalies, ankyloblepharon, oral synechiae, and nail abnormalities. Both conditions can arise as the result of mutations in IRF6 which encodes a transcription factor characterised by a highly conserved, helix-turn-helix DNA-binding domain and a less well-conserved protein interaction domain [30]. The mutations in IRF6 are non-randomly distributed with VWScausing mutations being evenly divided between protein truncation and missense variants while the majority of PPS-causing mutations are missense changes that cluster in the DNA-binding domain and affect amino acid residues predicted to contact DNA directly [30,35]. It is estimated that IRF6 mutations account for $70 \%$ of cases of VWS and $97 \%$ of cases of PPS [35].

A second VWS locus was mapped to human chromosome 1p34 [36] and VWS was confirmed to be genetically heterogeneous by the demonstration that mutations in the transcription factor Grainyhead-like 3 (GRHL3) underlie VWS in a subset of IRF6-negative families [37]. Transfection of GRHL3 mutation variants into zebrafish embryos abrogated periderm development via a dominantnegative effect, while all Grh/3-null mouse embryos developed abnormal periderm resulting in cleft palate in $17 \%$ of cases [37], confirming that VWS2 is also a peridermopathy. A common risk variant (rs41268753; p.Thr454Met) in the GRHL3 coding sequence is also an important contributor to nonsyndromic cleft palate $[38,39]$. Notably, this variant has been shown to disrupt periderm development in zebrafish [38].

Bartsocas Papas syndrome is a debilitating autosomal recessive disorder characterised by multiple popliteal pterygia, cutaneous syndactyly, lack of nails, ankyloblepharon, filiform bands between the jaws, hypoplastic external genitalia, cleft lip and/or palate, and fetal or neonatal lethality, although, in the latter case, survival into childhood and beyond has been reported [40]. Through a combination of exome sequencing and homozygosity mapping, homozygous mutations in the gene encoding RIPK4 were identified in individuals affected by Bartsocas Papas syndrome [32,33]. Ripk4 ${ }^{-1-}$ mouse embryos display epithelial fusions resulting from failure of periderm development thereby

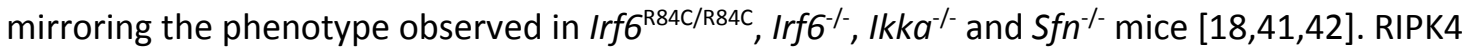
encodes a 784 amino acid receptor interacting serine/threonine kinase comprising a highly conserved $\mathrm{N}$-terminal kinase domain, a linker region, and a regulatory domain containing 11 ankyrin repeats towards the $\mathrm{C}$-terminus [43] with Bartsocas Papas syndrome mutations mainly affecting highly-conserved amino acid residues in the kinase domain. Mutations that arise in the ankyrin 
domains tend to cause the milder popliteal pterygium phenotype although the genotype-phenotype correlation is not absolute [34].

Cocoon syndrome (Severe Fetal Encasement Malformation) is the rarest and most severe of the conditions characterised by popliteal pterygia and has been shown to result from homozygous lossof-function mutations in IKKA [31]. Similar to the observations regarding RIPK4, mutations in IKKA cause a range of features along the Bartsocas Papas syndrome-cocoon syndrome spectrum, although the number of mutations identified to date is very small [34]. Notably, analysis of a human fetus affected by cocoon syndrome demonstrated the absence of periderm in regions of epithelial adhesion mirroring the findings made in $\mathrm{kk}^{-/}$embryos thereby confirming that failure of periderm formation underlies pathological adhesions in humans as well as mice [18] (Fig. 3).

\section{Molecular control of periderm development}

Although an embryonic barrier function has been assigned to periderm, the molecular events driving its development remain only partially elucidated. While IRF6, IKK $\alpha$, SFN and RIPK4 play a fundamental role in periderm formation, it is not clear how these proteins interact with one another and with additional components of the underlying gene regulatory network.

IRF6 binds to a conserved sequence conforming to the interferon-stimulated response element $[44,45]$ and promotes periderm differentiation by direct regulation of $G r h / 3$ expression [46]. Despite this observation, sub-cellular localisation studies have indicated that IRF6 localises to the cytoplasm $[23,24,47,48]$ suggesting that IRF6, as observed for other IRF family members, exists in an autoinhibited state until activated by phosphorylation [49]. While IKK $\alpha$ is critical for normal differentiation of epidermal keratinocytes, this function is independent of its kinase function [50]. In contrast, RIPK4 phosphorylates IRF6 to drive nuclear translocation and regulate its trans-activator activity, mutations in the kinase domain of RIPK4 that underlie Bartsocas-Papas syndrome disrupting this activity [42,51]. Mutagenesis assays identified Ser413 and Ser424 as the key regulatory phosphorylation sites in IRF6 [52]. Comparison with IRF3, which also exists in an auto-inhibited state until activated by phosphorylation, suggests a two-step activation model in which phosphorylation of Ser424 causes reorganisation of the auto-inhibitory structure leading to unmasking of a hydrophobic active site, phosphorylation of Ser 413 , and realignment of the DNA binding domain for transcriptional activation [53,54]. Interestingly, RIPK4 is activated by over-expression of IRF6 in vitro suggesting that IRF6 initially stimulates RIPK4 which subsequently amplifies IRF6 activity [42]. Overexpression of RIPK4 has also been shown to promote Wnt signalling, an activity that is dependent on its kinase activity and which is abrogated by mutations that underlie Bartsocas Papas syndrome [55]. Although RIPK4 phosphorylates the Dishevelled protein DVL2 directly [55], the role of increased Wnt signalling in periderm development has not been determined.

While the kinase function of IKK $\alpha$ is dispensable for keratinocyte differentiation, stratifin is downregulated in IKK $\alpha$-deficient keratinocytes, reintroduction of IKK $\alpha$ restoring the SFN expression [56]. Although a biochemical interaction between IRF6 and stratifin/IKK $\alpha$ has not been demonstrated, Irf6 and $S f n$ interact epistatically to control periderm development [23].

Recently, we have shown that several genes required for periderm development, including Irf6, Ripk4, Sfn, Grh/3 and Jag2, are direct transcriptional targets of $p 63$ and that periderm is absent in p63-null mice [57]. Paradoxically, in light of the finding that periderm is essential to prevent pathological adhesions between apposed epithelial surfaces, this phenotype is not observed in $p 63-$ 
null mice [58,59]. However, in addition to its effect on genes involved in periderm development, loss of p63 leads to down-regulation of adherens junction- and desmosome-associated genes in the basal epithelia thereby preventing intra-oral fusions from occurring despite the absence of periderm [57].

\section{Periderm and fusion of the palatal shelves}

Given that periderm acts as a protective barrier to prevent premature adhesion of juxtaposed epithelial surfaces during embryogenesis, this cell layer must be removed from the medial edge of the palatal shelves at a precise time to allow adhesion and subsequent fusion of the secondary palate. While some studies have suggested that periderm undergoes apoptosis and is sloughed from the leading edges of the facial primordia and the medial edge epithelia of the palatal shelves immediately prior to contact [60-63], others have shown that palatal shelf contact is achieved via the periderm $[13,57,64]$. While these different observations may be due to molecular heterogeneity along the antero-posterior axis of the palatal shelves [65], studies using vital dye staining, molecular markers, and transgenic reporter lines have indicated that after initial contact, periderm migration is essential to prevent cleft palate $[13,57,64,66]$. For example, Cuervo and Covarrubias selectively labelled the periderm cells with 5-6-carboxy 2-7-dichlorofluorescein diacetate succinimidyl ester and showed that the periderm cells migrated to the oral and nasal ends of the midline epithelial seam to contribute to the formation of the oral and nasal epithelial triangles where they underwent apoptosis [13]. Similarly, Richardson and co-workers used a transgenic reporter mouse in which the 5 ' upstream sequence from the mouse keratin 17 gene directs GFP expression in ectoderm-derived epithelial appendages during embryonic development [67] together with confocal imaging to demonstrate that periderm cells migrated out of the midline seam to the epithelial triangles and into the oral and nasal epithelia of the palatal shelves allowing palatal fusion to be completed [57] (Fig. 4). While one potential criticism of these studies is that they were performed using an ex vivo culture system, forced (premature) contact of the palatal shelves was avoided by ensuring that the palatal shelves had already achieved contact in vivo prior to their dissection [57].

In an elegant recent study, Kim and colleagues used a multifaceted approach to demonstrate several novel aspects of cell behaviour during fusion of the palatal shelves [68]. Using confocal live cell imaging, the authors showed that contact between the paired palatal shelves was achieved initially by cellular protrusions from the medial edge epithelia that reached across to form junctions with cells from the opposite palatal shelf leading to the formation of a multi-layered epithelial seam. Subsequently, driven by an actomyosin contractility pathway involving Rho kinase and myosin light chain kinase, culminating in activation of non-muscle myosin IIA, cell intercalation and orthogonal cell displacement resulted in convergence into a single-layer epithelium. Subsequently, apoptotic cell extrusion and extrusion-independent apoptosis, which occurred in approximately equal numbers of cells, mediated mesenchymal continuity across the secondary palate [68]. Although periderm fate was not analysed in this study, it is tempting to speculate that periderm migration from the midline seam is driven by actomyosin contractility with the periderm cells dying in the epithelial triangles [13] and the basal cells undergoing apoptosis in situ.

\section{Molecular control of oral periderm development}

As outlined above, IKK $\alpha$, SFN, RIPK4 and IRF6 all play an essential role in periderm formation, mice carrying loss-of-function mutations in the genes encoding these proteins exhibiting severe intra-oral adhesions that occluded the oral cavity and prevented palatal shelf elevation resulting in cleft 
palate. However, one of the first insights into the function of periderm was provided by the analysis of Jag 2 mutant mice $[8,11]$. Although palatal development initially proceeded normally, aberrant intra-oral adhesions formed between the vertical palatal shelves and the lateral aspect of the tongue at E12 resulting in cleft palate in Jag2 ${ }^{\triangle D S L / \triangle D S L}$ mice [8]. Casey and co-workers further demonstrated that Jag2, which is expressed throughout the oral epithelium until E14.5 when it is down-regulated in the medial edge epithelium, activates the Notch1 receptor in the oral periderm [8]. Notably, Notch1 activation was markedly reduced in the poorly differentiated periderm of Jag2-null mice [8].

Building on these observations, Richardson and colleagues analysed the intra-oral phenotype of Irf6 $6^{\mathrm{R} 4 \mathrm{C} / \mathrm{R} 8 \mathrm{C} C}$ mice and showed that a complete failure of periderm formation led to severe intra-oral adhesions that were apparent from the earliest stages of, and persisted throughout, development of the secondary palate resulting in total occlusion of the oral cavity and cleft palate [69]. The same authors also demonstrated epistasis between $I r f 6$ and Jag 2 with $/ r f 6^{+/ R 84 C} ; J a g 2^{+/ \Delta D S L}$ mice displaying a failure to activate Notch signaling in the oral periderm, disrupted periderm differentiation, intra-oral adhesions, and cleft palate [69]. However, the authors concluded that the phenotype observed in Irf6 ${ }^{+/ R 84 C} ; J a g 2^{+/ \Delta D S L}$ embryos was unlikely to result from disruption of a protein-protein interaction between IRF6 and Jagged2, or from a failure of one molecule to activate transcription of the other, and speculated that the mechanism underlying the Irf6-Jag2 genetic interaction resulted from their combined effects on periderm formation, maintenance and function [69]. In this context, recent experiments have shown that IRF6 function in both basal and periderm cells is necessary for appropriate development of the oral epithelia [70].

As outlined above, p63 plays a key role in periderm formation and maintenance. It is therefore notable that while p63 expression is down-regulated in the medial edge epithelia of wild-type embryos prior to palatal fusion [71], p63 expression is maintained in $\mathrm{Tgfb3}^{-/}$and $\mathrm{Tgfbr} \mathrm{fl}^{\mathrm{fl} / \mathrm{fl}}$; Krt14-cre mice which exhibit cleft palate as a result of palatal fusion abnormalities $[57,63,72-74]$. To assess whether down-regulation of $\mathrm{p} 63$ in the medial edge epithelia of wild-type mice was a prerequisite for, or a consequence of, palatal fusion, Richardson and colleagues manipulated the level of p63 in the medial edge epithelia of $T g \mathrm{fb}^{-/-}$mice genetically [57]. Although the vast majority of $\mathrm{Tg} \mathrm{fb}^{-/-}$mice exhibited cleft palate, the medial edge epithelia of $88.9 \%$ of their $\mathrm{Tgfb3}^{-/-} ; \mathrm{p63}^{+/-}$littermates adhered to form a midline seam which subsequently degenerated to allow fusion of the secondary palate supporting the hypothesis that epistatic down-regulation of $p 63$ in $\mathrm{Tgfb}^{-/}$embryos rescues the cleft palate phenotype (Fig. 4). Unlike the cell behaviour observed in $\mathrm{Tgfb}^{-/-}$embryos, the medial edge

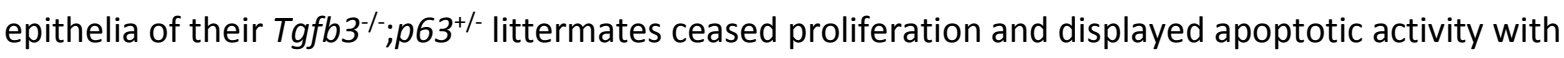
the periderm cells migrating out of the midline seam (Fig. 4). Further support for the downregulation of $\mathrm{p} 63$ being essential for palatal fusion was provided by the generation of transgenic mice in which $\Delta \mathrm{Np} 63 \alpha$ was over-expressed constitutively in the palatal epithelia with $70 \%$ of $\mathrm{Krt5}$ tTA;pTRE- $\Delta$ Np63 $\alpha$ bi-transgenic embryos displaying a persistent midline epithelial seam consisting of non-migratory periderm overlying a layer of proliferative basal cells [57]. Furthermore, the expression of a variety of genes which are normally down-regulated in the medial edge epithelia of wild-type mice, including adhesion molecules, $B c / 11 b$ and Jag2, was maintained in $\mathrm{Krt5}$-tTA;PTRE$\triangle N p 63 \alpha$ embryos [57]. On the basis of these combined results, the authors concluded that TGF $\beta 3$ mediated, down-regulation of p63 in the medial edge epithelia allows periderm migration out of the midline epithelial seam and reduces the proliferative potential of the midline epithelial seam thereby preventing cleft palate. 
p63 and TGF 33 also appear to function in concert with IRF6 to drive medial edge epithelial cell fate. In light of the phenotypic overlap exhibited by syndromes resulting from mutations in p63 and IRF6, Thomason and co-workers demonstrated that $p 63$ and Irf6 interact epistatically, $p 63^{+/-} ; / r f 6^{+/ R 84 C}$ mice exhibiting cleft palate [71]. The organisation of the medial edge epithelia was shown to be disturbed in $p 63^{+/-} ;$Irf $6^{+/ R 84 C}$ mice embryos with abnormal periderm cells persisting over the medial edge after the palatal shelves had fused in wild-type embryos. p63 was subsequently shown to trans-activate IRF6 by direct binding to a conserved enhancer located $\sim 10 \mathrm{~kb}$ upstream of the transcription start site [71]; the single nucleotide polymorphism rs642961 which lies within this enhancer disrupting a binding site for the transcription factor AP-2 $\alpha$ being associated with non-syndromic cleft lip [75]. Activation of IRF6 by p63 was abrogated by DNA-binding mutations that underlie EctrodactylyEctodermal dysplasia-Clefting syndrome. Thomason and colleagues also noted that the downregulation of p63 observed in wild-type mice failed to occur in the presumptive medial edge epithelia of their Irf6 ${ }^{R 84 C / R 84 C}$ littermates; consequently, the medial edge epithelia remained intact at the sites of ectopic adhesion [71]. This situation, which is in contrast to that observed in Jag2 ${ }^{\triangle D S L / \triangle D S L}$ and Irf6 ${ }^{+/ R 84 C} ; J a g 2^{+/ \Delta D S L}$ mice $[11,69]$, suggested a feedback loop between $\mathrm{p} 63$ and IRF6. In this regard, Moretti and colleagues showed a reciprocal relationship between IRF6 and p63 both in vivo and in vitro and demonstrated that wild-type IRF6, unlike Arg84Cys mutant IRF6, targets p63 to proteosomal degradation, p63 harbouring mutations that cause Ectrodactyly-Ecctodermal dysplasiaClefting syndrome being resistant to IRF6-mediated down-regulation [76]. Together, these observations demonstrate that IRF6 and p63 function in a regulatory feedback loop to control epithelial proliferation and differentiation that this module is disrupted by mutations that cause cleft lip and palate [77].

As noted above, Grhl3 plays a central role in periderm development. Similar to Grhl3, Klf17 acts downstream of Irf6 in zebrafish periderm [78]. However, in mammals, where Klf17 is not expressed in the oral epithelia, Irf6 appears to regulate peridermal expression of KIf4 via one or more evolutionarily-conserved, long-range enhancer elements [78]. Irf6 and Spry4 have also been shown to interact genetically to regulate periderm differentiation and function with loss of IRF6 and overexpression of SPRY4 appearing to converge on GRHL3 expression [79]. Other molecules that have been implicated in oral periderm ontogeny include FGF10 and FGFR2B, pathological intra-oral

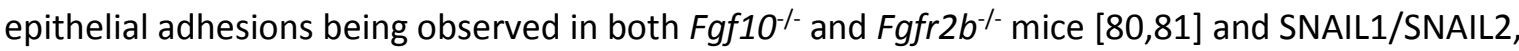
periderm migration out of the midline seam apparently failing to occur in Snai1 ${ }^{+/} ;$Snai ${ }^{-/}$embryos [64]; however, detailed studies of periderm development have not been performed in these mutant strains.

\section{Conclusions}

In summary, while periderm plays a critical barrier function during embryonic development by preventing pathological adhesion of intimately apposed, adhesion-competent epithelia with periderm migration from the midline epithelial seam being a pre-requisite for fusion of the secondary palate, other functions, such as an outside-inside diffusion barrier, have not been investigated. Similarly, while a subset of the molecules driving periderm formation/maintenance has been identified, further research is essential to dissect the underlying gene regulatory networks. 


\section{Acknowledgements}

The authors would like to thank current and former members of the Dixon laboratory and all past and present clinical and scientific collaborators.

\section{Funding}

This work was supported by the Medical Research Council (grant number MR/M012174/1) and the Wellcome Trust Institutional Strategic Support Fund (grant number 097820).

\section{References}

1. P.A. Mossey, J. Little, R.G. Munger, M.J. Dixon, W.C. Shaw, Cleft lip and palate, Lancet 374 (2009) 1773-1785.

2. M.J. Dixon, M.L. Marazita, T.H. Beaty, J.C. Murray, Cleft lip and palate: understanding genetic and environmental influences. Nat. Rev. Genet. 12 (2011) 167-178.

3. D.R. FitzPatrick, P.A. Raine, J.G. Boorman, Facial clefts in the west of Scotland in the period 1980-1984: epidemiology and genetic diagnoses, J. Med. Genet. 31 (1994) 126-129.

4. A. Gritli-Linde, Molecular control of secondary palate development, Dev. Biol. 301 (2007) 309326.

5. J.O. Bush, R. Jiang, Palatogenesis: morphogenetic and molecular mechanisms of secondary palate development, Development 139 (2012) 231-243.

6. Y. Lan, J. Xu, R. Jiang, Cellular and molecular mechanisms of palatogenesis, Curr. Top. Dev. Biol. 115 (2015) 59-84.

7. Y. Ito, J.Y. Yeo, A. Chytil, J. Han, P. Bringas Jr, A. Nakajima, C.F. Shuler, H.L. Moses, Y. Chai, Conditional inactivation of Tgfbr2 in cranial neural crest causes cleft palate and calvaria defects, Development 130 (2003) 5269-5280.

8. L.M. Casey, Y. Lan, E.S. Cho, K.M. Maltby, T. Gridley, R. Jiang, Jag2-Notch1 signaling regulates oral epithelial differentiation and palate development, Dev. Dyn. 235 (2006) 1830-1844.

9. T. Humphrey, Palatopharyngeal fusion in a human fetus and its relation to cleft formation, Alabama J. Med. Sci. 7 (1970) 398-429.

10. R.M. Shah, Palatomandibular and maxillo-mandibular fusion, partial aglossia and cleft palate in a human embryo. Report of a case, Teratology 15 (1977) 261-272.

11. R. Jiang, Y. Lan, H.D. Chapman, C. Shawber, C.R. Norton, D.V. Serreze, G. Weinmaster, T. Gridley, Defects in limb, craniofacial, and thymic development in Jagged2 mutant mice, Genes Dev. 12 (1998) 1046-1057.

12. F. Cecconi, G. Alvarez-Bolado, B.I. Meyer, K.A. Roth, P. Gruss, Apaf1 (CED-4 homolog) regulates programmed cell death in mammalian development, Cell 94 (1998) 727-737.

13. R. Cuervo, L. Covarrubias, Death is the major fate of medial edge epithelial cells and the cause of basal lamina degradation during palatogenesis, Development 131 (2004) 15-24.

14. F. Vaziri Sani, V. Kaartinen, M. El Shahawy, A. Linde, A. Gritli-Linde A, Developmental changes in cellular and extracellular structural macromolecules in the secondary palate and in the nasal cavity of the mouse, Eur. J. Oral Sci. 118 (2010) 221-236.

15. T. Lechler, E. Fuchs, Asymmetric cell divisions promote stratification and differentiation of mammalian skin, Nature 437 (2005) 275-280.

16. Y. M'Boneko, H.J. Merker, Development and morphology of the mouse embryos (days 9-12 of gestation), Acta Anat. 133 (1988) 325-336. 
17. K.M. McGowan, P.A. Coulombe PA, Onset of keratin 17 expression coincides with the definition of major epithelial lineages during skin development, J. Cell Biol. 143 (1998) 469-486.

18. R.J. Richardson, N.L. Hammond, P.A. Coulombe, C. Saloranta, H.O. Nousiainen, R. Salonen, A. Berry, N. Hanley, D. Headon, R. Karikoski, M.J. Dixon, Periderm prevents pathological epithelial adhesions during embryogenesis, J Clin. Invest. 124 (2014) 3891-3900.

19. M.J. Hardman, S. Paraskevi, D.N. Banbury, C. Byrne, Patterned acquisition of skin barrier function during development, Development 125 (1998) 1541-1552.

20. M.J. Hardman, L. Moore, M.W.J. Ferguson, C. Byrne, Barrier formation in the human fetus is patterned, J. Invest. Dermatol. 113 (1999) 1106-1113.

21. C.Y. Cui, M. Kunisada, D. Esibizione, S.I. Grivennikov, Y. Piao, S.A. Nedospasov, D. Schlessinger, Lymphotoxin-beta regulates periderm differentiation during embryonic skin development, Hum. Mol. Genet. 16 (2007) 2583-2590.

22. J. Okano, U. Lichti, S. Mamiya, M. Aronova, G. Zhang, S.H. Yuspa, H. Hamada, Y. Sakai, M.I. Morasso, Increased retinoic acid levels through ablation of Cyp26b1 determine the processes of embryonic skin barrier formation and peridermal development, J. Cell Sci. 125 (2012) $1827-$ 1836.

23. R.J. Richardson, J. Dixon, S. Malhotra, M.J. Hardman, L. Knowles, R.P. Boot-Handford, P. Shore, A. Whitmarsh, M.J. Dixon, IRF6 is a key determinant of the keratinocyte proliferation/ differentiation switch, Nat. Genet. 38 (2006) 1329-1334.

24. C.R. Ingraham, A. Kinoshita, S. Kondo, B. Yang, S. Sajan, K.J. Trout, M.I. Malik, M. Dunnwald, S.L. Goudy, M. Lovett, J.C. Murray, B.C. Schutte, Abnormal skin, limb and craniofacial morphogenesis in mice deficient for interferon regulatory factor 6 (Irf6), Nat. Genet. 38 (2006) 1335-1340.

25. Y. Hu, V. Baud, M. Delhase, P. Zhang, T. Deerinck, M. Ellisman, R. Johnson, M. Karin, Abnormal morphogenesis but intact IKK activation in mice lacking the IKKalpha subunit of IkappaB kinase, Science 284 (1999) 316-320.

26. Q. Li, Q. Lu, J.Y. Hwang, D. Büscher, K.F. Lee, J.C. Izpisua-Belmonte, I.M. Verma, IKK1-deficient mice exhibit abnormal development of skin and skeleton, Genes Dev. 13 (1999) 1322-1328.

27. K. Takeda, O. Takeuchi, T. Tsujimura, S. Itami, O. Adachi, T. Kawai, H. Sanjo, K. Yoshikawa, N. Terada, S. Akira, Limb and skin abnormalities in mice lacking IKKalpha, Science 284 (1999) 313316.

28. B.J. Herron, R.A. Liddell, A. Parker, S. Grant, J. Kinne, J.K. Fisher, L.D. Siracusa, A mutation in stratifin is responsible for the repeated epilation (Er) phenotype in mice, Nat. Genet. 37 (2005) 1210-1212.

29. Q. Li, Q. Lu, G. Estepa, I.M. Verma, Identification of 14-3-3sigma mutation causing cutaneous abnormality in repeated-epilation mutant mouse, Proc. Natl. Acad. Sci. USA 102 (2005) 1597715982.

30. S. Kondo, B.C. Schutte, R.J. Richardson, B.C. Bjork, A.S. Knight, Y. Watanabe, E. Howard, R.L.L. Ferreira de Lima, S. Daack-Hirsch, A. Sander, D.M. McDonald-McGinn, E.H. Zackai, E. Lammer, A. Aylsworth, H. Ardinger, B. Pober, C. Houdayer, M. Bahuau, D. Moretti-Ferreira, A. Richieri-Costa, M.J. Dixon, J.C. Murray, Mutations in IRF6 cause Van der Woude and popliteal pterygium syndromes, Nat. Genet. 32 (2002) 285-289.

31. J. Lahtela, H.O. Nousiainen, V. Stefanovic, J. Tallila, H. Viskari, R. Karikoski, M. Gentile, C. Saloranta, T. Varilo, R. Salonen, M. Kestilä, Mutant CHUK and severe fetal encasement malformation, N. Engl. J. Med. 363 (2010) 1631-1637. 
32. K. Mitchell, J. O'Sullivan, C. Missero, E. Blair, R. Richardson, B. Anderson, D. Antonini, J.C. Murray, A.L. Shanske, B.C. Schutte, R.A. Romano, S. Sinha, S.S. Bhaskar, G.C. Black, J. Dixon, M.J. Dixon, Exome sequence identifies RIPK4 as the Bartsocas-Papas syndrome locus, Am. J. Hum. Genet. 90 (2012) 69-75.

33. E. Kalay, O. Sezgin, V. Chellappa, M. Mutlu, H. Morsy, H. Kayserili, E. Kreiger, A. Cansu, B. Toraman, E.M. Abdalla, Y. Aslan, S. Pillai, N.A. Akarsu, Mutations in RIPK4 cause the autosomalrecessive form of popliteal pterygium syndrome, Am. J. Hum. Genet. 90 (2012) 76-85.

34. E.J. Leslie, J. O'Sullivan, M.L. Cunningham, A. Singh, S.L. Goudy, F. Ababneh, L. Alsubaie, G.S. Ch'ng, I.M. van der Laar, A.J. Hoogeboom, M. Dunnwald, S. Kapoor, P. Jiramongkolchai, J. Standley, J.R. Manak, J.C. Murray, M.J. Dixon, Expanding the genetic and phenotypic spectrum of popliteal pterygium disorders, Am. J. Med. Genet. A. 167A (2015) 545-552.

35. R.L. de Lima, S.A. Hoper, M. Ghassibe, M.E. Cooper, N.K. Rorick, S. Kondo, L. Katz, M.L. Marazita, J. Compton, S. Bale, U. Hehr, M.J. Dixon, S. Daack-Hirsch, O. Boute, B. Bayet, N. Revencu, C. Verellen-Dumoulin, M. Vikkula, A. Richieri-Costa, D. Moretti-Ferreira, J.C. Murray, B.C. Schutte, Prevalence and nonrandom distribution of exonic mutations in interferon regulatory factor 6 in 307 families with Van der Woude syndrome and 37 families with popliteal pterygium syndrome, Genet. Med. 11 (2009) 241-247.

36. H. Koillinen, F.K. Wong, J. Rautio, V. Ollikainen, A. Karsten, O. Larson, B.T. Teh, J. Huggare, P. Lahermo, C. Larsson, J. Kere, Mapping of the second locus for the Van der Woude syndrome to chromosome 1p34, Eur. J. Hum. Genet. 9 (2001) 747-752.

37. M. Peyrard-Janvid, E.J. Leslie, Y.A. Kousa, T.L. Smith, M. Dunnwald, M. Magnusson, B.A. Lentz, P. Unneberg, I. Fransson, H.K. Koillinen, J. Rautio, M. Pegelow, A. Karsten, L. Basel-Vanagaite, W. Gordon, B. Andersen, T. Svensson, J.C. Murray, R.A. Cornell, J. Kere, B.C. Schutte, Dominant mutations in GRHL3 cause Van der Woude Syndrome and disrupt oral periderm development, Am. J. Hum. Genet. 94 (2014) 23-32.

38. E.J. Leslie, H. Liu, J.C. Carlson, J.R. Shaffer, E. Feingold, G. Wehby, C.A. Laurie, D. Jain, C.C. Laurie, K.F. Doheny, T. McHenry, J. Resick, C. Sanchez,J. Jacobs, B. Emanuele, A.R. Vieira, K. Neiswanger, J. Standley, A.E. Czeizel, F. Deleyiannis, K. Christensen, R.G. Munger, R.T. Lie, A. Wilcox, P.A. Romitti, L.L. Field, C.D. Padilla, E.M. Cutiongco-de la Paz, A.C. Lidral, L.C. ValenciaRamirez, A.M. Lopez-Palacio, D.R. Valencia, M. Arcos-Burgos, E.E. Castilla, J.C. Mereb, F.A. Poletta, I.M. Orioli, F.M. Carvalho, J.T. Hecht, S.H. Blanton, C.J. Buxó, A. Butali, P.A. Mossey, W.L. Adeyemo, O. James, R.O. Braimah, B.S. Aregbesola, M.A. Eshete, M. Deribew, M. Koruyucu, F. Seymen, L. Ma, J.E. de Salamanca, S.M. Weinberg, L. Moreno, R.A. Cornell, J.C. Murray, M.L. Marazita, A genome-wide association study of nonsyndromic cleft palate identifies an etiologic missense variant in GRHL3, Am. J. Hum. Genet. 98 (2016) 744-754

39. E. Mangold, A.C. Böhmer, N. Ishorst, A.K. Hoebel, P. Gültepe, H. Schuenke, J. Klamt, A. Hofmann, L. Gölz, R. Raff, P. Tessmann, S. Nowak, H. Reutter, A. Hemprich, T. Kreusch, F.J. Kramer, B. Braumann, R. Reich, G. Schmidt, A. Jäger, R. Reiter, S. Brosch, J. Stavusis, M. Ishida, R. Seselgyte, G.E. Moore, M.M. Nöthen, G. Borck, K.A.Aldhorae, B. Lace, P. Stanier, M. Knapp, K.U. Ludwig, Sequencing the GRHL3 coding region reveals rare truncating mutations and a common susceptibility variant for nonsyndromic cleft palate, Am. J. Hum. Genet. 98 (2016) 755 762.

40. H.E. Veenstra-Knol, A. Kleibeuker, A. Timmer, L.P. ten Kate, A.J. van Essen, Unreported manifestations in two Dutch families with Bartsocas-Papas syndrome, Am. J. Med. Genet. 123A (2003) 243-248. 
41. R.B. Rountree, C.R. Willis, H. Dinh, H. Blumberg, K. Bailey, C. Dean Jr, J.J. Peschon, P.M. Holland, RIP4 regulates epidermal differentiation and cutaneous inflammation, J. Invest. Dermatol. 130 (2010) 102-112.

42. P. De Groote, H.T. Tran, M. Fransen, G. Tanghe, C. Urwyler, B. De Craene, K. Leurs, B. Gilbert, G. Van Imschoot, R. De Rycke, C.J. Guérin, P. Holland, G. Berx, P. Vandenabeele, S. Lippens, K. Vleminckx, W. Declercq, A novel RIPK4-IRF6 connection is required to prevent epithelial fusions characteristic for popliteal pterygium syndromes, Cell Death Differ. 22 (2015) 1012-1024.

43. E. Meylan, J. Tschopp, The RIP kinases: crucial integrators of cellular stress. Trends Biochem. Sci. 30 (2005) 151-159.

44. H.J. Little, N.K. Rorick, L.I. Su, C. Baldock, S. Malhotra, T. Jowitt, L. Gakhar, R. Subramanian, B.C. Schutte, M.J. Dixon, P. Shore, Missense mutations that cause Van der Woude syndrome and popliteal pterygium syndrome affect the DNA-binding and transcriptional activation functions of IRF6, Hum. Mol. Genet. 18 (2009) 535-545.

45. E. Botti, G. Spallone, F. Moretti, B. Marinari, V. Pinetti, S. Galanti, P.D. De Meo, F. De Nicola, F. Ganci, T. Castrignanò, G. Pesole, S. Chimenti, L. Guerrini, M. Fanciulli, G. Blandino, M. Karin, A. Costanzo, Developmental factor IRF6 exhibits tumor suppressor activity in squamous cell carcinomas, Proc. Natl. Acad. Sci. USA. 108 (2011) 13710-13715.

46. G. de la Garza, J.R. Schleiffarth, M. Dunnwald, A. Mankad, J.L. Weirather, G. Bonde, S. Butcher, T.A. Mansour, Y.A. Kousa, C.F. Fukazawa, D.W. Houston, J.R. Manak, B.C. Schutte, D.S. Wagner, R.A. Cornell, Interferon regulatory factor 6 promotes differentiation of the periderm by activating expression of Grainyhead-like 3, J. Invest. Dermatol. 133 (2013) 68-77.

47. C.M. Bailey, D.E. Abbott, N.V. Margaryan, Z. Khalkhali-Ellis, M.J. Hendrix MJ, Interferon regulatory factor 6 promotes cell cycle arrest and is regulated by the proteasome in a cell cycledependent manner, Mol. Cell Biol. 28 (2008) 2235-2243.

48. C.M. Bailey, N.V. Margaryan, D.E. Abbott, B.C. Schutte, B. Yang, Z. Khalkhali-Ellis, M.J. Hendrix, Temporal and spatial expression patterns for the tumor suppressor Maspin and its binding partner interferon regulatory factor 6 during breast development, Dev. Growth Differ. 51 (2009) 473-481.

49. W. Chen, W.E. Royer Jr, Structural insights into interferon regulatory factor activation, Cell Signal. 22 (2010) 883-887.

50. Y. Hu, V. Baud, T. Oga, K.I. Kim, K. Yoshida, M. Karin, IKKalpha controls formation of the epidermis independently of NF-kappaB, Nature 410 (2001) 710-714

51. M.Q. Kwa, J. Huynh, J. Aw, L. Zhang, T. Nguyen, E.C. Reynolds, M.J. Sweet, J.A. Hamilton, G.M. Scholz, Receptor-interacting protein kinase 4 and interferon regulatory factor 6 function as a signaling axis to regulate keratinocyte differentiation, J. Biol. Chem. 289 (2014) 31077-31087.

52. M.Q. Kwa, T. Nguyen, J. Huynh, D. Ramnath, D. De Nardo, P.Y. Lam, E.C. Reynolds, J.A. Hamilton, M.J. Sweet, G.M. Scholz, Interferon regulatory factor 6 differentially regulates Toll-like receptor 2-dependent chemokine gene expression in epithelial cells, J. Biol. Chem. 289 (2014) 1975819768.

53. B.Y. Qin, C. Liu, S.S. Lam, H. Srinath, R. Delston, J.J. Correia, R. Derynck, K. Lin, Crystal structure of IRF-3 reveals mechanism of autoinhibition and virus-induced phosphoactivation, Nat. Struct. Biol. 10 (2003) 913-921.

54. D. Panne, S.M. McWhirter, T. Maniatis, S.C. Harrison, Interferon regulatory factor 3 is regulated by a dual phosphorylation-dependent switch, J. Biol. Chem. 282 (2007) 22816-22822. 
55. X. Huang, J.C. McGann, B.Y. Liu, R.N. Hannoush, J.R. Lill, V. Pham, K. Newton, M. Kakunda, J. Liu, C. Yu, S.G. Hymowitz, J.A. Hongo, A. Wynshaw-Boris, P. Polakis, R.M. Harland, V.M. Dixit, Phosphorylation of Dishevelled by protein kinase RIPK4 regulates Wnt signaling, Science 339 (2013) 1441-1445.

56. F. Zhu, X. Xia, B. Liu, J. Shen, Y. Hu, M. Person, IKKalpha shields 14-3-3sigma, a G(2)/M cell cycle checkpoint gene, from hypermethylation, preventing its silencing, Mol Cell. 27 (2007) 214-227.

57. R. Richardson, K. Mitchell, N.L. Hammond, M.R. Mollo, E.N. Kouwenhoven, N.D. Wyatt, I.J. Donaldson, L. Zeef, T. Burgis, R. Blance, S.J. van Heeringen, H.G. Stunnenberg, H. Zhou, C. Missero, R.A. Romano, S. Sinha, M.J. Dixon, J. Dixon, p63 exerts spatio-temporal control of palatal epithelial cell fate to prevent cleft palate, PLoS Genet. 13 (2017) e1006828.

58. H.A. Thomason, M.J. Dixon, J. Dixon, Facial clefting in Tp63 deficient mice results from altered Bmp4, Fgf8 and Shh signaling, Dev. Biol. 321 (2008) 273-282.

59. R.A. Romano, K. Smalley, C. Magraw, V.A. Serna, T. Kurita, S. Raghavan, S. Sinha, $\Delta$ Np63 knockout mice reveal its indispensable role as a master regulator of epithelial development and differentiation, Development 139 (2012) 772-782.

60. D. Sun, S. Baur, E.D. Hay, Epithelial-mesenchymal transformation is the mechanism for fusion of the craniofacial primordia involved in morphogenesis of the chicken lip, Dev. Biol. 228 (2000) 337-349.

61. J.E. Fitchett, E.D. Hay, Medial edge epithelium transforms to mesenchyme after embryonic palatal shelves fuse, Dev. Biol. 131 (1989) 455-474.

62. M. Yoshida, Y. Shimono, H. Togashi, K. Matsuzaki, J. Miyoshi, A. Mizoguchi, T. Komori, Y. Takai, Periderm cells covering palatal shelves have tight junctions and their desquamation reduces the polarity of palatal shelf epithelial cells in palatogenesis, Genes Cells 17 (2012) 455-472.

63. L. Hu, J. Liu, Z. Li, F. Ozturk, C. Gurumurthy, R.A. Romano, S. Sinha, A. Nawshad, TGFß3 regulates periderm removal through $\triangle N p 63$ in the developing palate, J. Cell Physiol. 230 (2015) 12121225.

64. S.A. Murray, K.F. Oram, T. Gridley, Multiple functions of Snail family genes during palate development in mice, Development 134 (2007) 1789-1797.

65. S.A. Hilliard, L. Yu, S. Gu, Z. Zhang, Y.P. Chen, Regional regulation of palatal growth and patterning along the anterior-posterior axis in mice, J Anat. 207 (2005) 655-667.

66. M.J. Carette, M.W. Ferguson, The fate of medial edge epithelial cells during palatal fusion in vitro: an analysis by Dil labelling and confocal microscopy, Development 114 (1992) 379-388.

67. N. Bianchi, D. DePianto, K. McGowan, C. Gu, P.A. Coulombe, Exploiting the keratin 17 gene promoter to visualize live cells in epithelial appendages of mice, Mol. Cell. Biol. 25 (2005) 7249725.

68. S. Kim, A.E. Lewis, V. Singh, X. Ma, R. Adelstein, J.O. Bush, Convergence and extrusion are required for normal fusion of the mammalian secondary palate, PLoS Biol. 13 (2015) e1002122.

69. R.J. Richardson, J. Dixon, R. Jiang, M.J. Dixon, Integration of IRF6 and Jagged2 signalling is essential for controlling palatal adhesion and fusion competence, Hum. Mol. Genet. 18 (2009) 2632-2642.

70. Y.A. Kousa, D. Moussa, B.C. Schutte, IRF6 expression in basal epithelium partially rescues Irf6 knockout mice. Dev. Dyn. doi: 10.1002/dvdy.24537

71. H.A. Thomason, H. Zhou, E.N. Kouwenhoven, G.P. Dotto, G. Restivo, B.C. Nguyen, H. Little, M.J. Dixon, H. van Bokhoven, J. Dixon, Cooperation between the transcription factors p63 and IRF6 is essential to prevent cleft palate in mice, J Clin. Invest. 120 (2010) 1561-1569. 
72. G. Proetzel, S.A. Pawlowski, M.V. Wiles, M. Yin, G.P. Boivin, P.N. Howles, J. Ding, M.W. Ferguson, $T$. Doetschman, Transforming growth factor-beta 3 is required for secondary palate fusion, Nat. Genet. 11 (1995) 409-414.

73. V. Kaartinen, J.W. Voncken, C. Shuler, D. Warburton, D. Bu, N. Heisterkamp, J. Groffen, Abnormal lung development and cleft palate in mice lacking TGF-beta 3 indicates defects of epithelial-mesenchymal interaction, Nat. Genet. 11 (1995) 415-421.

74. J. Iwata, A. Suzuki, R.C. Pelikan, T.V. Ho, P.A. Sanchez-Lara, M. Urata, M.J. Dixon, Y. Chai, Smad4Irf6 genetic interaction and TGF $\beta$-mediated IRF6 signaling cascade are crucial for palatal fusion in mice, Development 140 (2013) 1220-1230.

75. F. Rahimov, M.L. Marazita, A. Visel, M.E. Cooper, M.J. Hitchler, M. Rubini, F.E. Domann, M. Govil, K. Christensen, C. Bille, M. Melbye, A. Jugessur, R.T. Lie, A.J. Wilcox, D.R. Fitzpatrick, E.D. Green, P.A. Mossey, J. Little, R.P. Steegers-Theunissen, L.A. Pennacchio, B.C. Schutte, J.C. Murray, Disruption of an AP-2alpha binding site in an IRF6 enhancer is associated with cleft lip, Nat. Genet. 40 (2008) 1341-1347.

76. F. Moretti, B. Marinari, N. Lo lacono, E. Botti, A. Giunta, G. Spallone, G. Garaffo, E. VernerssonLindahl, G. Merlo, A.A. Mills, C. Ballarò, S. Alemà, S. Chimenti, L. Guerrini, A. Costanzo, A regulatory feedback loop involving p63 and IRF6 links the pathogenesis of 2 genetically different human ectodermal dysplasias, J. Clin. Invest. 120 (2010) 1570-1577.

77. A. Gritli-Linde, p63 and IRF6: brothers in arms against cleft palate, J. Clin. Invest. 120 (2010) 1386-1389.

78. H. Liu, E.J. Leslie, Z. Jia, T. Smith, M. Eshete, A. Butali, M. Dunnwald, J. Murray, R.A. Cornell, Irf6 directly regulates KIf17 in zebrafish periderm and KIf4 in murine oral epithelium, and dominantnegative KLF4 variants are present in patients with cleft lip and palate, Hum. Mol. Genet. 25 (2016) 766-776.

79. Y.A. Kousa, R. Roushangar, N. Patel, A. Walter, P. Marangoni, R. Krumlauf, O.D. Klein, B.C. Schutte, IRF6 and SPRY4 Signaling Interact in Periderm Development, J. Dent. Res. doi: 10.1177/0022034517719870.

80. R. Rice, B. Spencer-Dene, E.C. Connor, A. Gritli-Linde, A.P. McMahon, C. Dickson, I. Thesleff, D.P. Rice, Disruption of Fgf10/Fgfr2b-coordinated epithelial-mesenchymal interactions causes cleft palate, J. Clin. Invest. 113 (2004) 1692-1700.

81. S.R. Alappat, Z. Zhang, K. Suzuki, X. Zhang, H. Liu, R. Jiang, G. Yamada, Y. Chen, The cellular and molecular etiology of the cleft secondary palate in Fgf10 mutant mice, Dev. Biol. 277 (2005) 102-113. 


\section{Figure legends}

Figure 1: Secondary palate development in the mouse. (A) Time-course of palatogenesis in mice outlining the major developmental processes. (B-D) Scanning electron micrographs showing oral views of the secondary palate at representative developmental stages. Fusion of the palatal shelves in the midline is arrowed. (E-M) Histological sections from anterior (E-G), mid ( $\mathrm{H}-\mathrm{J})$, and posterior (K$\mathrm{M})$ regions of the developing palate at each of the stages indicated. The mid palate is flanked by developing molar tooth germs (black arrows) and corresponds to the palatine region of the future hard palate. The posterior region corresponds to the future soft palate. $(E, H, K)$ At E13.5, the palatal shelves exhibit distinct shapes along the antero-posterior axis. $(F, I, L)$ By E14.0, the palatal shelves have elevated to a horizontal position above the dorsum of the tongue. (G, J, M) At E14.5, the palatal shelves have contacted via the medial edge epithelia to form a midline epithelial seam which has started to degenerate. ns, nasal septum; pp, primary palate; $p$, palatal shelf; $t$, tongue. Scale bars: $300 \mu \mathrm{m}$.

Figure 2: Periderm development in the epidermis. (A) Schematic diagram illustrating the normal programme of periderm development in the epidermis with a key depicting the relevant cell types. (B-F) Dual immunofluorescence for p63 (red) and keratin 17 (K17; green) reveals K17-positive periderm cells above a single layer of p63-positive basal cells from E11.5. As the epidermis differentiates, $\mathrm{K} 17$ expression persists until E15.5 when it is down-regulated in periderm and upregulated in placodes and hair follicles. (G-K) Keratin 6 (K6; green) is expressed in the periderm from E13.5 and is present in shedding periderm at E17.5. (L-P) Markers of terminal differentiation such as loricrin (Lor; green) are expressed as barrier formation proceeds in a patterned fashion from late E15. Periderm detaches from the cornified layer in a similar pattern. Nuclei are counterstained with DAPI. The dotted lines represent the approximate position of the basement membrane in B-P. Scale bars: $25 \mu \mathrm{m}$. Modified from [18]. Note that the spinous layer is not present in the developing oral ectoderm prior to fusion of the secondary palate.

Figure 3: Failure of periderm formation results in pathological adhesions during embryogenesis. $(A, C, E G)$ At E9, prior to periderm formation, the ectoderm cells of the developing epidermis are highly polarised in both wild-type and $I \mathrm{kka}^{-/}$mice. $(\mathrm{A}, \mathrm{C}) \mathrm{ZO} 1$, a tight junction component, is expressed on the apico-lateral surface of the single-layered ectoderm cells thereby restricting expression of the adherens junction component E-cadherin to the apico-basal membranes. $(\mathrm{E}, \mathrm{G})$ The apical membranes express the polarity marker, atypical protein kinase C (aPKC). (B,F) At E14, ZO1 and aPKC show a similar polarised expression pattern in the developing epidermis of wild-type mice. $(\mathrm{D}, \mathrm{H})$ In contrast, the lack of periderm formation in the epidermis of $/ \mathrm{kg}^{-/-}$mouse embryos results in adhesion complexes such as adherens junctions being expressed on the apical surface of the exposed cells (arrows). (I-N) The lack of barrier function provided by the periderm results in the epithelial surfaces of the maxillary $(\mathrm{mx})$ and mandibular $(\mathrm{md})$ processes adhering to one another in $I k^{-/-}$mice (I-K) and inter-epithelial adhesions forming between the hind-limbs in human (L-N) embryos carrying a homozygous loss-of-function mutation in IKKA. Periderm is marked by keratin 17 (K17) in mouse embryos and keratin 6 (K6) in human embryos. Nuclei are counterstained with DAPI. The dotted line indicates the approximate position of the basement membrane. Scale bars: A-H, 10 $\mu \mathrm{m} ; \mathrm{I}, \mathrm{J}, \mathrm{L}, \mathrm{M}, 50 \mu \mathrm{m}$. Modified from [18]. 
Figure 4: Periderm removal from the midline epithelial seam. (A) Schematic diagram illustrating the sequence of events during fusion of the secondary palate. (B) In wild-type mouse embryos, the horizontal palatal shelves contact via the keratin 17-expressing periderm cells (red arrows) which begin to remodel (orange arrowheads). (C, D) After palatal shelf contact, periderm cells migrate out of the midline seam (green arrows) towards the oral and nasal epithelia to form the oral and nasal epithelial triangles (white arrowheads). (E-G) While the palatal shelves of wild-type mice adhere via the medial edge epithelia and form a midline seam (E), the palatal shelves of $T g \mathrm{fb}^{-/-}$mice fail to adhere and form a midline seam with the palatal shelves remaining cleft (F). (G) Reducing p63 dosage in the medial edge epithelia of $T g \mathrm{fb}^{-/-}$mice restores the wild-type phenotype. (H-J) Keratin 17-positive periderm cells migrate out of the midline seam to form the oral and nasal epithelial

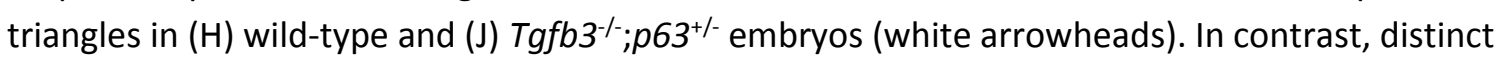
keratin 14-positive basal and keratin 17-positive periderm layers persist and the palatal shelves fail to adhere and fuse in $\mathrm{Tgfb}^{-\%}$ mice. (B-D,H-J) Nuclei are counterstained with DAPI. p, palatal shelf; $t$, tongue. Scale bars: B-D, $50 \mu \mathrm{m} ; \mathrm{E}-\mathrm{G}, 250 \mu \mathrm{m} ; \mathrm{H}-\mathrm{J}, 100 \mu \mathrm{m}$. Modified from [57]. 
Figr-1

A
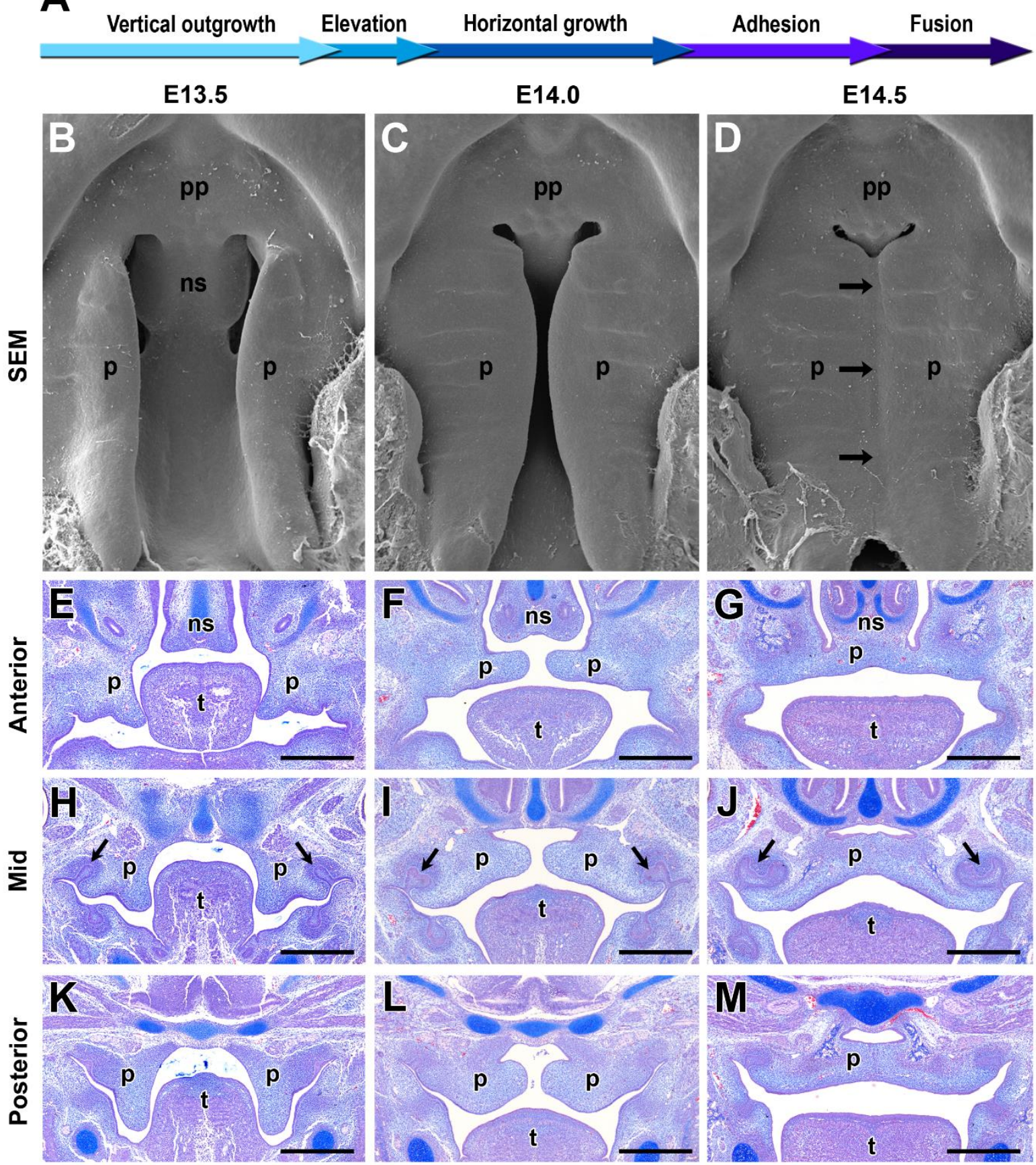
Figr-2
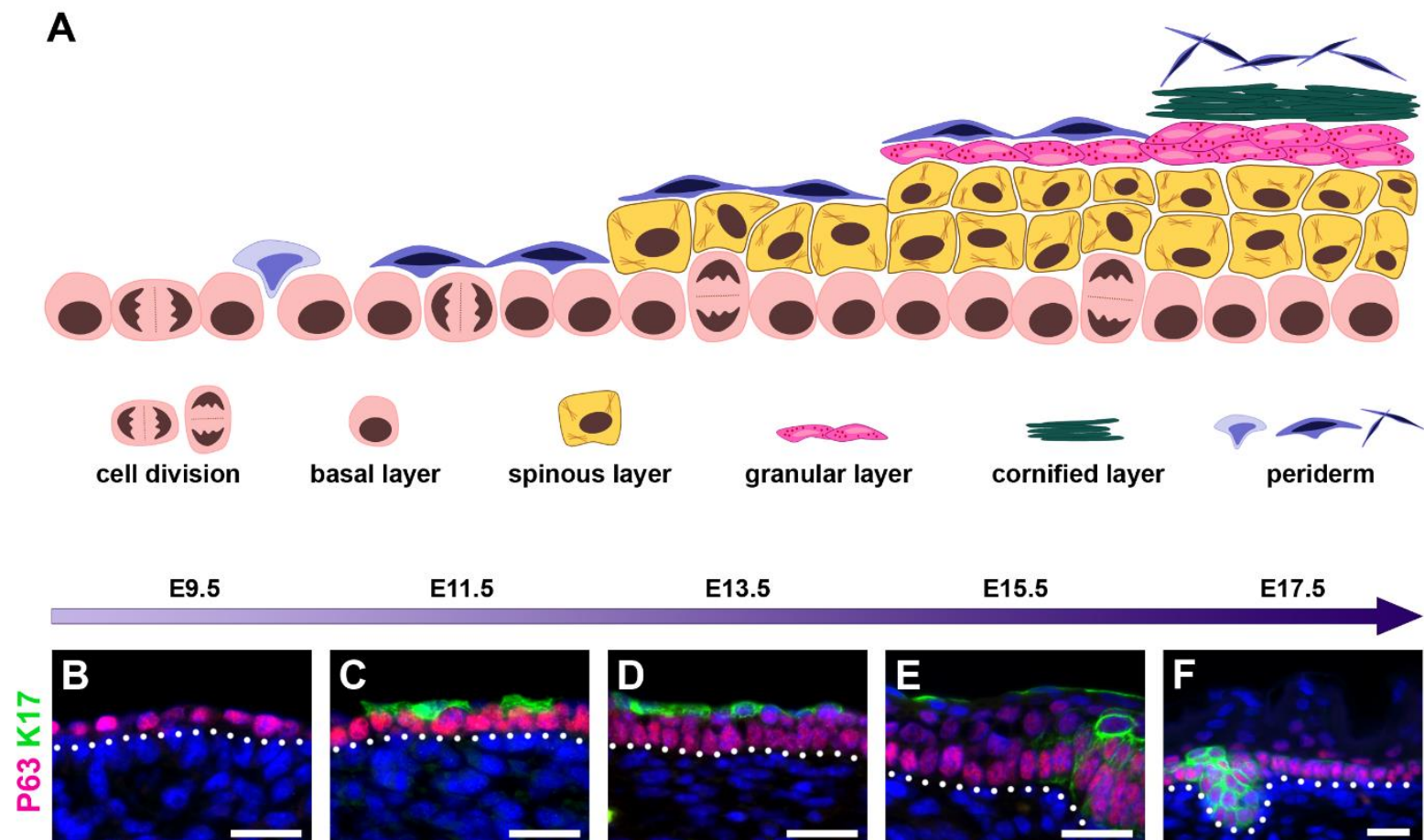

E11.5

E13.5

E15.5

E17.5
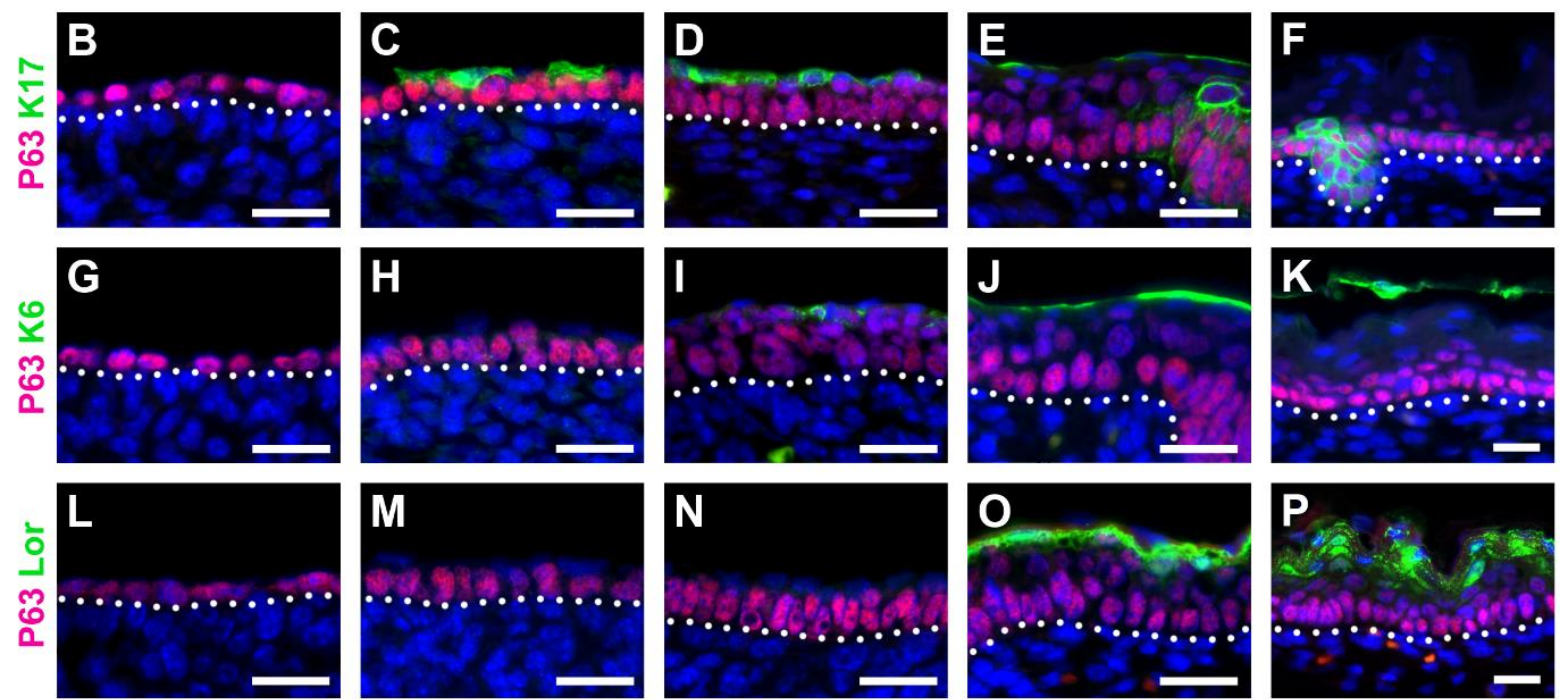
Figr-3
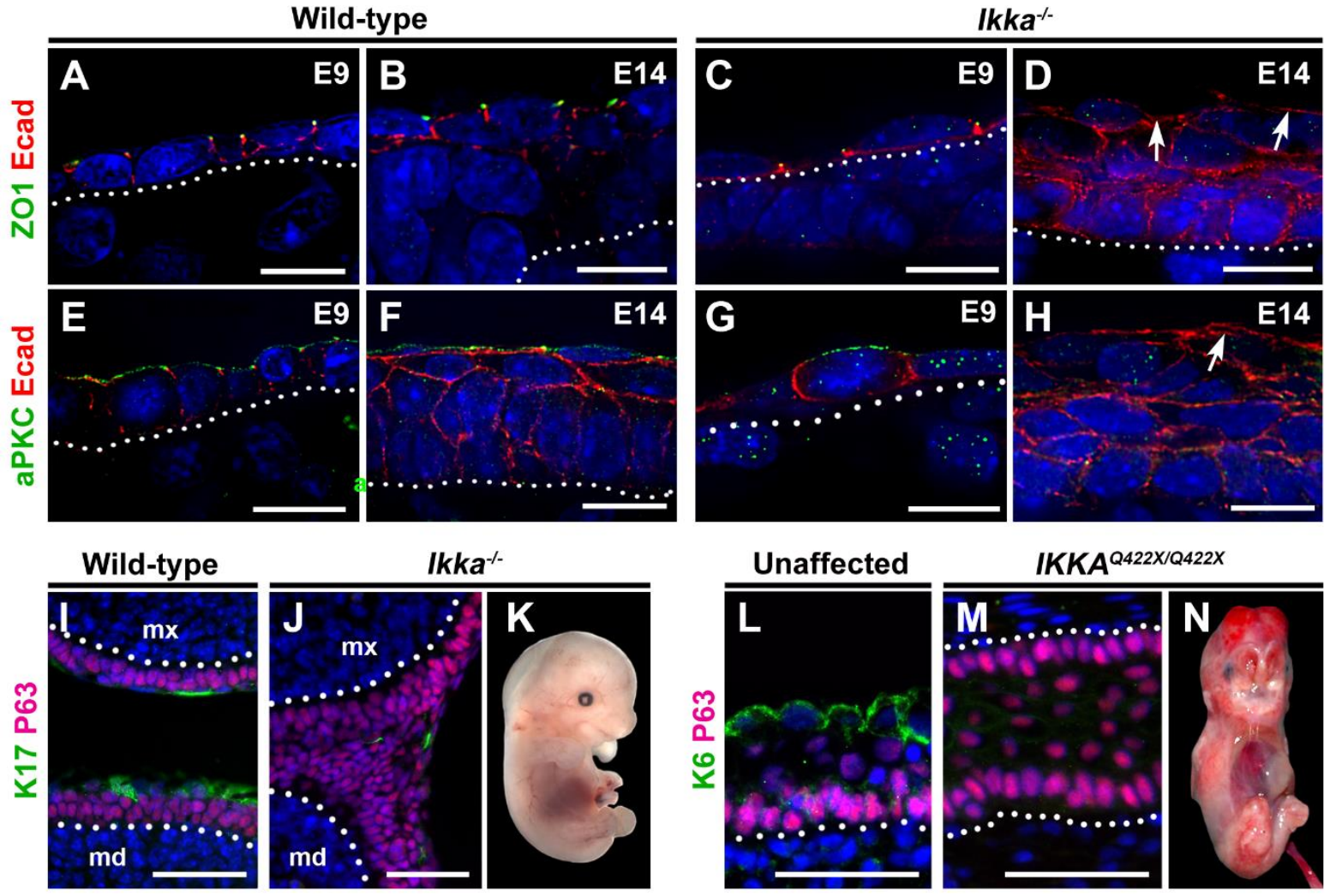
Figr-4

\section{A}

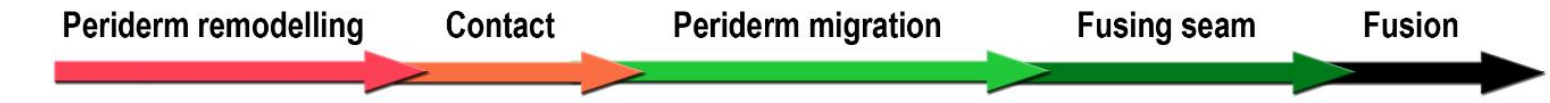

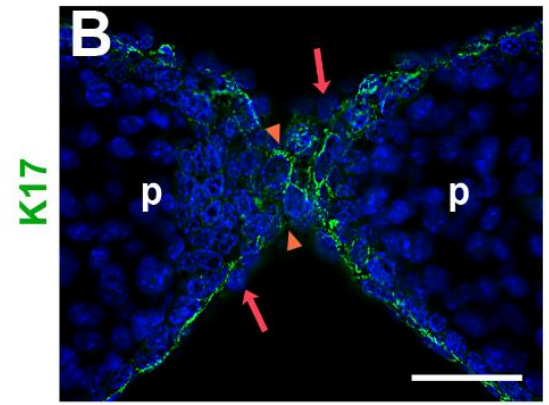

Wild-type
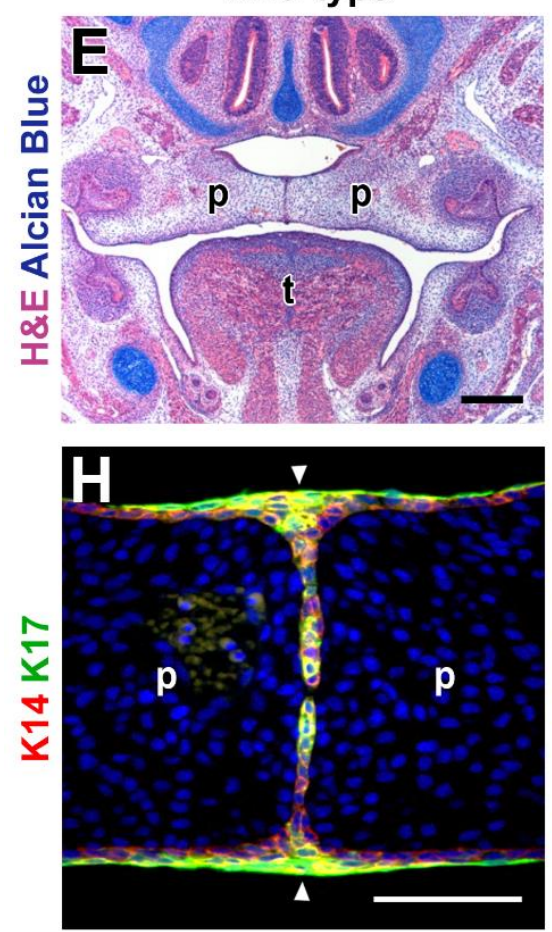

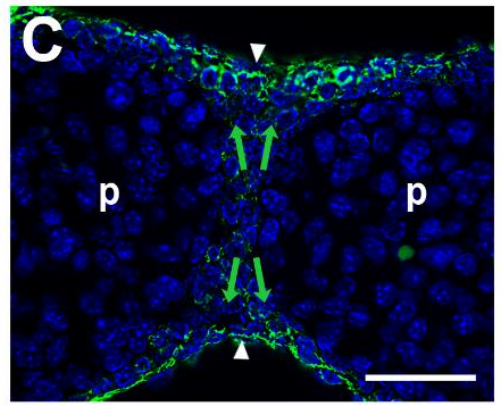

Tgfb3-/-
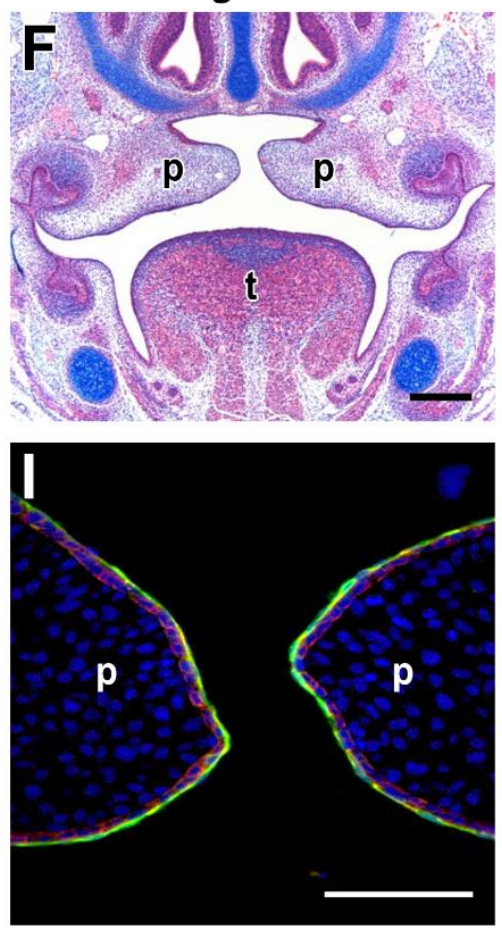

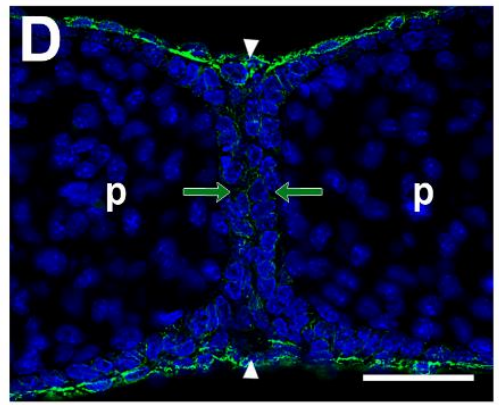

Tgfb3 $^{-/-} ; p 63^{+/-}$
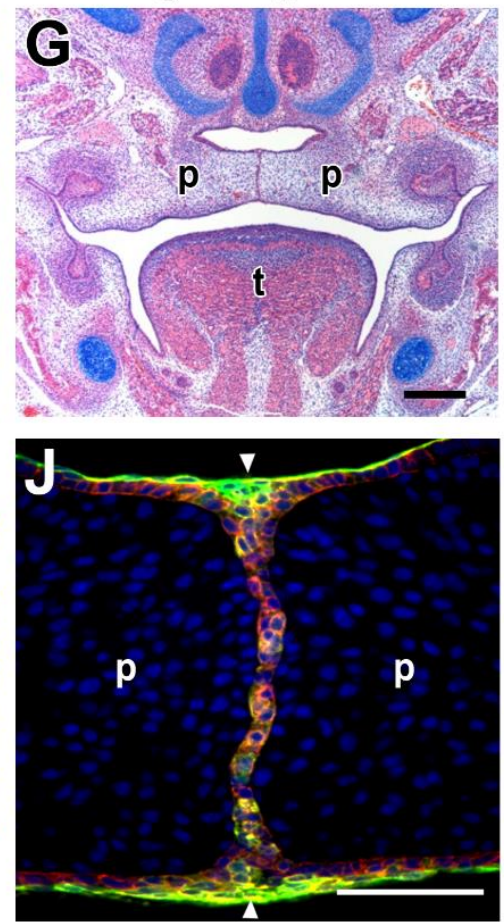